\title{
Value of hip B-mode gray scale histogram in the diagnosis of Graf Type Ila physiologically immature hip
}

\section{Graf Tip Ila fizyolojik inmatür kalça tanısında B-mod gri skala histogramın değeri}

\author{
Bülent ÇEKiçç, İclal ERDEM TOSLAK ${ }^{1}$, Yavuz YÜKSEL ${ }^{2}$, Semih SAĞLIK ${ }^{3}$, Adil GÖKMEN ${ }^{4}$, Özkan KÖSE ${ }^{4}$
}

\section{ABSTRACT}

The objectives of this study are to measure femur head echogenicity in newborns with physiologic immature hips (type 2a), to compare it with cases with mature type 1 a hips and to reveal the value of femur head echogenicity in the evaluation of physiologically immature hips. This study consisted of 65 type $1 a$ and 65 type $2 a$ physiologically immature hip joints detected in the radiology clinic, and categorized according to the Graf classification. Only 8-week-old newborns were included in the study in order to avoid differences that might arise from patients' age. Femoral head echogenicity was measured by software available on the ultrasonic device and hip joint ultrasound according to each newborn Graf method. Femur head echogenicity histogram values were $69.44 \pm 2.87$ in type 1a group, and $57.55 \pm 2.92$ in type $2 a$ group and there was a significant difference between both groups $(p<0,05)$. The echogenicity values of the subgroups of Type $2 a(2 a(+)$ and $2 a(-))$ were $59.30 \pm 1.70$ and $54.34 \pm 1.69$, respectively, and there was a significant difference between the two groups $(p<0,05)$. A positive correlation was found between the hip joint alpha angle and femoral head echogenicity histogram values $(r=0.953, p<0.001)$. Type 2 a physiologically immature neonates have significantly lower femoral head echogenicity measured with the $B$ mode histogram method compared with the type 1a maturation group. We think that there is a significant positive correlation between alpha angle and femoral head echogenicity which is a sign of physiological immaturity.

Keywords: Type 2a, femur echogenicity, histogram
Öz

Bu çalışmanın amacı, Graf sınıflandırmasına göre fizyolojik inmatür (tip 2a) yenidoğanlarda femur başı ekojenitesini ölçmek ve matür tip 1a olan olgular ile karşılaştırmak, fizyolojik immatür kalçalar tanısında femur başı ekojenitesinin değerini ortaya koymaktır. Bu çalışma, radyoloji kliniğinde graf sınıflamasına göre 65 tip 1 a matür ve 65 tip 2 a fizyolojik immatür kalçası olan yenidoğandan oluşmaktaydı. Yaşdan kaynaklanabilecek farklılıkların önüne geçebilmek için yalnızca 8 haftalık yenidoğanlar çalışmaya dahil edildi. Her yenidoğana Graf yöntemine göre kalça eklemi ultrasonografisi ve ultrason cihazında var olan yazılım ile femur başı ekojenitesi ölçüldü. Tip 1a grubunda femur başı ekojenitesi

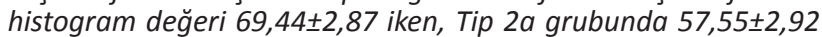
bulunmuş olup her iki grup arasında anlamlı farklılık saptanmış$\operatorname{tir}(p<0,05)$. Tip $2 a^{\prime} n ı n$ alt grupları olan $2 a(+)$ ve $2 a(-)$ ekojenite

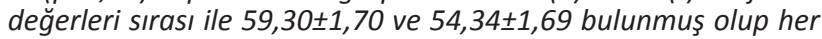
iki grup arasında anlamlı farklılık saptanmıştır $(p<0,05)$. Kalça eklemi alfa açıları ile femur başı ekojenite histogram değerleri arasında pozitif korelasyon saptandı $(r=0,953, p<0,001)$. Tip 2 a fizyolojik immatür yenidoğanlarda, tip 1a matür grup ile karşılaştırıldığında femur başı ekojenitesi B mod histogram yöntemi ile anlamlı olarak düşüktür. Alfa açıları ile femur başı ekojenitesi arasında anlamlı pozitif korelasyon mevcut olup, fizyolojik immatüritenin bir göstergesi olduğunu düşünmekteyiz.

\section{Giriş}

Gelişimsel kalça displazisi (GKD); yenidoğan döneminde erken tanı ve tedavi ile sekelleri kolaylıkla önlenebilen klinik bir tablodur. Klinik muayeneye ek olarak ultrason kullanımına bağlı GKD sıklığı \%0,5 ile $\% 1,5$ arasında değiştiği bildirilmiştir ${ }^{1,2}$. Günümüzde
Anahtar kelimeler: Tip 2a, femur ekojenite, histogram

Received: 01.06 .2017

Accepted: 14.06 .2017

${ }^{1}$ Department of Radiology; ${ }^{4}$ Department of Orthopedics, Antalya Training and Research Hospital, Antalya, Turkey

${ }^{2}$ Department of Radiology, Afyon Şuhut State Hospital, Afyon, Turkey

${ }^{3}$ Department of Radiology, Siirt State Hospital, Siirt, Turkey

Yazışma adresi: Bülent Çekiç, Department of Radiology, Antalya Training and Research Hospital, Antalya, Turkey

e-mail: bulend71@yahoo.com

GKD tanısında ultrason kullanılarak yapılan Graf sınıflaması altın standart olarak kabul edilmektedir ${ }^{3}$.

Kalça eklemi gelişimi, fetal dönemde başlayıp yenidoğan döneminde devam eden dinamik bir süreç olup, ilk 3 aylık dönemde femur başı-asetabulum ilişkisi matürasyonu gecikmesi Graf sınıflamasına göre tip 2a 
fizyolojik immatürite olarak adlandırılmaktadır ${ }^{4}$. Graf sınıflamasına göre Tip 2a sıklığı yapılan çalışmalarda kullanılan modaliteye bağlı olarak \%5 ile \%45 arasında değişmektedir. Bunun yanında, tip 2a kalçalarda spontan matürasyon \%97 oranında izlenirken, kalça matürasyonunda duraklama veya kötüleşme \%3 ile $\% 5$ arasında izlenmektedir ${ }^{5-8}$.

Gri skala histogram yöntemi yardımcı bir ultrason yöntemi olup, görüntüdeki her bir pikseldeki ekojenite değerlerini kantitatif veri olarak bize sunmaktadır.

Bizim bu çalışmamızdaki amacımız, Graf sınıflandırmasına göre fizyolojik immatür (tip 2a) yenidoğanlarda femur başı ekojenitesini ölçmek ve matür tip 1a olan yendioğanlar ile karşılaştırmak, graf tip 2a fizyolojik immatür tanısında femur başı ekojenitesinin prediktif değerini ortaya koymaktır.

\section{GEREÇ ve YÖNTEM}

Çalışmaya Haziran 2016 ile Ocak 2017 tarihleri arasında Antalya Eğitim ve Araştırma Hastanesi Radyoloji Kliniğine başvurup kalça ultrasonu incelemesi yapılan, Graf sınıflandırmasına göre tip 2a (fizyolojik immatür) tanısı almış 65 yenidoğan ve 65 tip 1a matür yenidoğan dahil edilmiştir. Çalışmanın Etik Kurul onayı yerel Etik Kurulundan alınmış olup, çalışmaya katılan tüm yenidoğanların ebeveynleri çalışma hakkında bilgilendirilmiş ve aydınlatılmış onam alınmıştır.

Yenidoğanın haftasından kaynaklanabilecek femur başı ekojenite farklılıkların önüne geçebilmek için çaIışmamıza dahil ettiğimiz tüm yenidoğanların yaşı 8 . hafta olarak seçildi.

Kalça eklemi incelemesi için Hitachi brand ( $\mathrm{HI}$ vision Preirius, Tokyo, Japan) ultrason cihazı ve $7,5 \mathrm{mHz}$ lineer prob kullanıldı.

Kalça ultrasonu incelemesi yenidoğan lateral dekubitis pozisyonda, diz ve kalça eklemi semi fleksiyonda, 15-20 derece internal rotasyonda iken yapıldı. Trokanter major düzeyinde cilde metil sellülöz jel sürüldükten sonra prob cilde göre dik pozisyonda iken, kalça eklemin koronal planda görüntüleri alındı. Graf yöntemine göre asetabulumun en derin noktası, Y kıkırdağı, asetabular labrum ve iliak kanatın düz bir hat şeklinde görüldüğü anda ekrandaki görüntü donduruldu. Daha sonra iliak kanatdan referans çizgisi çizildi. Graf metoduna göre kalça eklemi sınıflandırılması alfa ve beta açısına göre yapıldı. Alfa açısı iliak kemiğe paralel geçen anahat ile iliumun ossifiye kesimi ile asetabulumdaki y kartilajdan geçen hat arasındaki açı olarak tanımlandı. Beta açısı ise iliumun ossifiye kesimi ile asetabular labrumdan geçen hat arasındaki açı olarak tanımlandı.

Alfa açısı 600 derecenin üstünde olanlar tip 1 matür, Alfa açısı 500-590 arasında olup, 3 ayın altında olanlar tip 2a, 3 ayın üstünde olanlar tip 2 b olarak sınıflandırıldı. Dört yüz otuz-dört yüz doksan aralığında olanlar sublukse, anstabl olarak bilinen tip $D$ ve 2c, 430 derecenin altında olanlar tip 3 disloke, 430 derecenin altında ile beraber ileri derecede displazi tip 4 olarak sınıflandıııldı ${ }^{3}$. Açı ölçümleri yapıldıktan sonra aynı görüntü üzerinde kullandığımız ultrason cihazında mevcut olan histogram yazılımı ile femur başı üzerinde $27 \times 25 \mathrm{~mm}$ boyutlarında dikdörtgen çizilip dikdörtgen içersinde kalan alanın ekojenitesi Ultrason cihazında var olan yazılım ile ölçülüp kaydedildi (Figür 1).

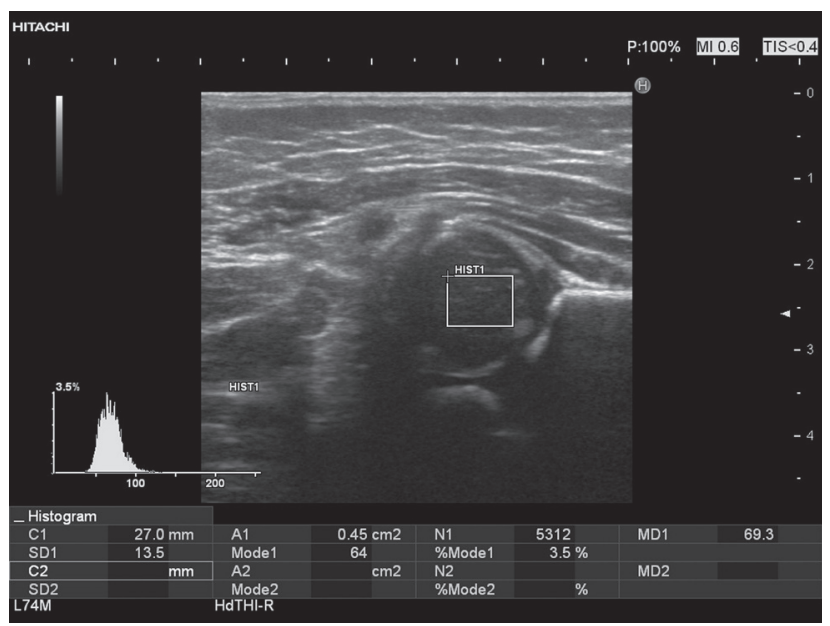

Figür 1. Femur başı ekojenite ölçümü ve histogram değerleri.

B-mod gri skala Histogram ölçüm yönteminde standartizasyonu sağlamak için zaman kazanç ayarı (TGC) aralığ -30 ile $30 \mathrm{db}$ arasında tutuldu. B mod kazanç aralığı 0 
ile 60 arasında olup, kullandığımız kazanç değeri 35 idi. Focus aralığı 0 ile 5 arasında olup, 2.5 seviye kullanıldı. Ekojenite değerleri 0-255 aralığında (0: siyah, 255: beyaz) seçilip histogram yöntemi kullanılarak ölçüldü.

\section{istatiksel yöntem}

Çalışmamızdaki tüm verilerin analizi PASW 18 yazılımı (SPSS/IBM, Chicago, IL, USA) kullanılarak yapıldı. Parametrik veriler student's t-testi ile parametrik olmayan veriler ki-kare testi kullanılarak analiz edildi. Alfa açıları ile femur başı ekojenite histogram değerleri arasındaki korelasyonu belirlemek için Pearson korelasyon testi kullanıldı. $p<0,05$ değeri anlamlı olarak kabul edildi.

\section{BULGULAR}

Çalışmamıza graf sınıflamasına göre 65 tip 1a, 65 tip 2a [41 tip 2a (+), 24 tip 2a (-)] olmak üzere yenidoğan dahil edilmiştir. Tip 1a grubunda 35 kı/30 erkek, Tip 2a grubunda $45 \mathrm{kı} / 20$ erkekten oluşmakta olup, her iki grubun cinsiyet dağılımı arasında istatiksel olarak anlamlı farklılık saptanmıştır $(p<0,05)$. Tip 1a grubun yaş ortalaması $34,26 \pm 1,48$ iken, Tip $2 a$ 'nın yaş ortalaması $35 \pm 1,27$ olup her iki grup arasında anlamlı farklılık saptanmamıştır $(p=0,190)$. Tip 1 a ve tip $2 a$ grupları arasında alfa ve beta açıları arasında anlamlı farklılık vardır $(p<0,05)$. Tip 1a grubunda femur başı ekojenitesi histogram değeri $69,44 \pm 2,87$ iken, Tip $2 a$

Tablo 1. Tip 1a ve Tip 2a gruplarındaki değişkenler.

\begin{tabular}{llll}
\hline & Tip 1a & Tip 2a & p değeri \\
\hline Cinsiyet (K/E) & $35 / 30$ & $45 / 20$ & $\mathrm{p}<0,05$ \\
Yaş (gün) & $34,26 \pm 1,48$ & $35 \pm 1,27$ & $\mathrm{p}=0,190$ \\
Alfa açıSı & $62,56 \pm 1,81$ & $55,89 \pm 2,36$ & $\mathrm{p}<0,05$ \\
Beta açıSı & $46,26 \pm 2,58$ & $49,81 \pm 3,09$ & $\mathrm{p}<0,05$ \\
Ekojenite değeri & $69,44 \pm 2,87$ & $57,55 \pm 2,92$ & $\mathrm{p}<0,05$ \\
& & & \\
\hline
\end{tabular}

$p<0.05$ anlamlı kabul edildi.

Tablo 2. Tip 2a (+) ve Tip 2a (-) grupları ekojenite değerleri.

\begin{tabular}{llll}
\hline & Tip 2a (+) & Tip 2a (-) & p değeri \\
\hline Ekojenite değeri & $59,30 \pm 1,70$ & $54,34 \pm 1,69$ & $p<0,05$ \\
\hline
\end{tabular}

grubunda 57,55 $\pm 2,92$ bulunmuş olup, her iki grup arasında anlamlı farklılık saptanmıştır $(p<0,05)($ Tablo 1). Tip $2 a^{\prime}$ nın alt grupları olan $2 a(+)$ ve 2 a (-) ekojenite değerleri sırası ile $59,30 \pm 1,70$ ve $54,34 \pm 1,69$ bulunmuş olup, her iki grup arasında anlamlı farklılık saptanmıştır $(p<0,05)$ (Tablo 2) (Figür 2). Kalça eklemi alfa açıları ile femur başı ekojenite histogram değerleri arasında pozitif korelasyon saptandı $(r=0,953$, $p<0,001$ ) (Figür 3).

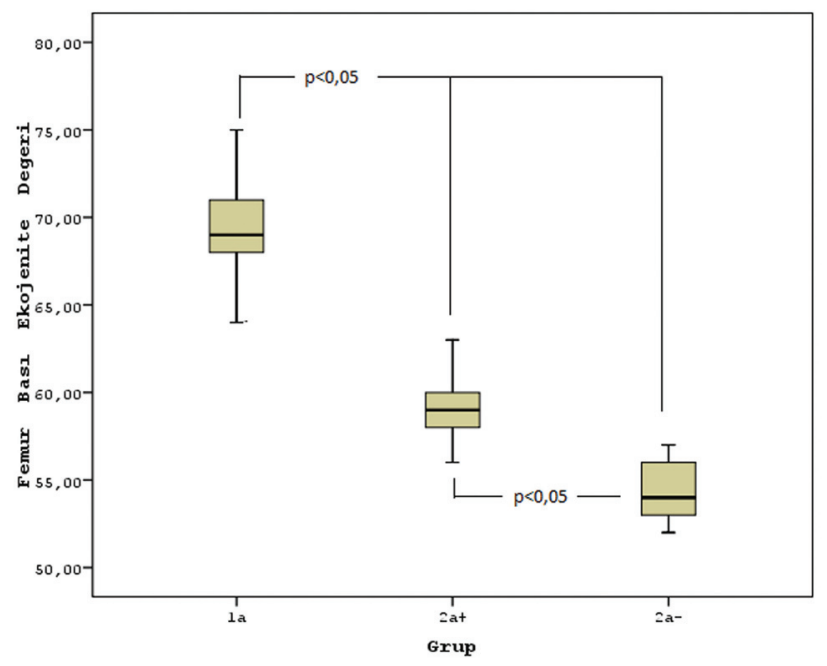

Figür 2. Tüm grupların femur ekojenite histogram değerleri.

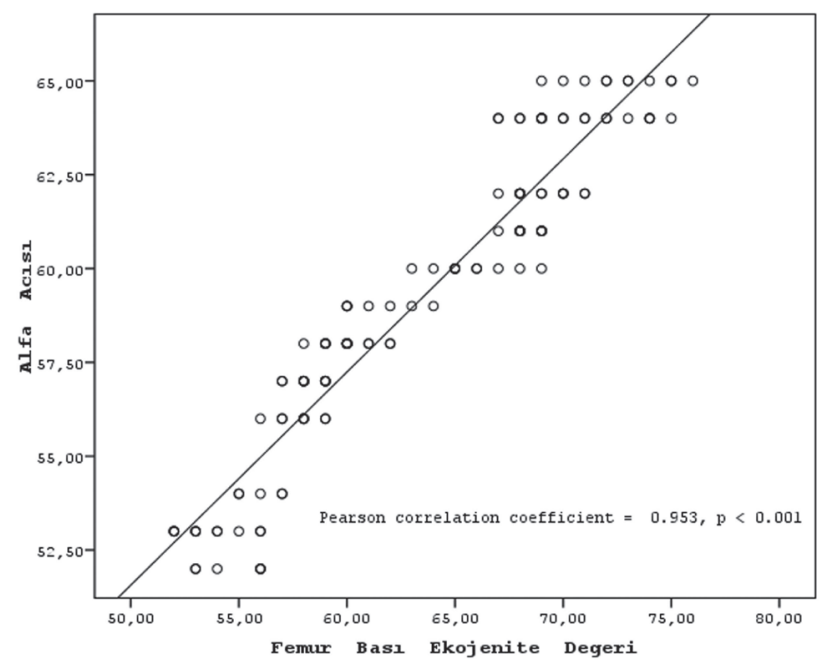

Figür 3. Alfa açısı ile femur ekojenite korelasyon değerleri.

\section{TARTIŞMA}

Çalışmamızda graf sınıflamasına göre fizyolojik immatür (tip 2a) olan yenidoğan femur başı ekojenitelerin, 
tip 1a matür grup ile karşılaştırıldığında anlamlı olarak azaldığını bulduk. Elde ettiğimiz veriler ışığında femur başı ekojenitesinin B-mod Histogram yöntemi ile ölçülmesinin, tip 1a ile tip 2a ayrımında ek yardımcı bir ultrason yöntemi olarak kullanılabileceğini düşünmekteyiz.

Yenidoğan döneminde yaşamın ilk üç aylık dönemde asetabular çatının kıkırdak yapıda olması nedeni ile bu dönemde GKD tanısında radyografinin kullanımı kısıtlıdır ${ }^{9}$. GKD erken tanısında ise artık günümüzde kalça eklemi US en güvenilir yöntem olarak kabul edilmektedir ${ }^{10}$. Graf yöntemine göre ultrason kullanılarak ülkemizde yenidoğanlarda yapılan çalışmalarda, fizyolojik immatür kalça olarak bilinen tip 2a kalça sıklığı \%1,2-7,9 arasında değiştiği bildirilmiştir6. illk US incelemede tip 2a lehine değerlendirilen kalçaların 3 ay içerisinde \%84-97'si kendiliğinden düzeldiği, \%3-5 oranda ise displaziye doğru ilerleme gösterdiği bildirilmiştir. Üçüncü ayında tip 1a kalçaya dönüşmeyen yenidoğanlarda ortopedik tedavi gerekliliği doğduğu belirtilmiştir ${ }^{6,11,12}$.

US yalnızca GKD tanısında değil aynı zamanda Graf sınıflandırılmasına göre tip 2a olan olguların takibinde kullanılmaktadır ${ }^{13}$. Graf sınıflamasına göre tip 2a kalçalar alfa açısının 50-55 derece arasında olanlar tip 2a (-), alfa açısı 55-60 derece arasında olanlar tip 2a (+) olarak adlandırılmaktadır ${ }^{6,11}$. Yapılan çalışmalarda tip 2a (-) kalçaların spontan düzleme oranlarının, tip 2a (+) ile karşılaştırıldığında daha düşük olduğu ve yakın takip gerekliliği olduğu belirtilmiştir ${ }^{12}$. Beş bin yüz yetmiş tip 2a tanılı yenidoğan bebeğin retrospektif incelenmesinde tip 2a (+) tanılı olanların \%95,3'te tip 2a (-) tanılı hastaların $\% 84,4$ 'te kendiliğinden düzelme görülmüştür ${ }^{14}$.

Yenidoğan döneminde kalça eklemi ultrason uygulaması kullanıcı deneyiminin öne çıktığı bir uygulamadır. Özellikle fizyolojik immatür olarak sınıflandırdığımız tip 2a hastalarda, tanıyı doğrulamak açısından ultrason ölçümlerin tekrarı gerekmektedir. Çalışmamızda kullandığımız yardımcı bir ultrason tekniği olan B mod histogram yöntemi her bir pikseldeki ekojenite değerlerini sayısal olarak verebilmekte, görün- tünün ekojenitesi hakkında kalitatif yerine kantitatif bilgiler verebilmektedir ${ }^{15}$. Çalışmamızda, femur başı ekojenitesi ile alfa açıları arasında güçlü pozitif korelasyon tesbit edilmesi olup, femur başı ekojenitesinin fizyolojik immatüritenin bir yansıması olduğunu ve kantitatif bir ölçüm olan B-mod Histogram yönteminin, fizyolojik immatürite tanısında tanısal değeri olduğunu düşünmekteyiz. Özellikle tip 2a'nın alt grubu olan, yakın klinik ve sonografik takibi gerektiren tip 2a (-) yenidoğanların tip 2a (+)'lardan istatiksel olarak anlamlı femur başı histogram değerleri olmasının bu grup hastaların klinik yönetiminde değerli olduğu kanısındayız.

Çalışmamızın kısıtlayan başlıca sınırlamalar ölçüm yaptığımız tip 2a yenidoğan grubunun çok geniş olmamasıdır. Bu konuda daha geniş hasta populasyonu ile yapılacak ölçümlerin femur başı histogram referans değerlerin oluşturulmasında katkı sağlayacağını inanmaktayız. Çalışmamızı sınırlayan diğer bir neden tip 2a tanılı hasta grubunun takiplerinde kendiliğinden düzelen veya düzelmeyenlerde femur başı ekojenitesinin ölçülemeyip, femur başı ekojenitesinin matürasyon süreci üzerine olan etkilerini belirleyememizdir. Kullandığımız B-mod Histogram ölçümleri; zaman kazanç ayarı, fokus aralığı ve kazanç değeri gibi ultrason parametrelerine bağımlı olup, bu parametrelerin standartizasyonu ile olası yanlış ölçümlerinden kaçınılabileceğini düşünmekteyiz.

Tip 2 a fizyolojik immatür yenidoğanlarda, tip 1a matür grup ile karşılaştırıldığında femur başı ekojenitesi B mod histogram yöntemi ile anlamlı olarak düşük bulunmuştur. Alfa açıları ile femur başı ekojenitesi arasında anlamlı pozitif korelasyon mevcut olup fizyolojik immatüritenin bir göstergesi olduğunu düşünmekteyiz. Femur başı ekojenitesinin B-mod Histogram yöntemi ile ölçülmesinin tip 2 a immatür kalça eklemlerin tanısında yardımcı bir sonografik yöntem olup, bununla beraber daha geniş hasta serileri ile yapılan çalışmaların referans değerlerin oluşturulmasında yararlı olacağına inanmaktayız. 


\section{KAYNAKLAR}

1. Köse N, Ömeroğlu H, Dağlar B. Gelişimsel Kalça Displazisi Ulusal Erken Tanı ve Tedavi Programı 2010; 4-5 http://www. bsm.gov.tr/duyuru Erişim tarihi: 09/02/2013.

2. Shipman SA, Helfand M, Moyer VA, Yawn BP. Screening for developmental dysplasia of the hip: A systematic literature review for the US preventive services task force. Pediatrics 2006;117:557-76.

https://doi.org/10.1542/peds.2005-1597

3. Graf R. Hip ultrasonography. Basic principles and current aspects. Orthopade 1997;26:14-24. https://doi.org/10.1007/s001320050065

4. Karapınar L, Surenkök F, Oztürk H, et al. The importance of predicted risk factors in developmental hip dysplasia:an ultrasonographic screening program. Acta Orthop Traumatol Turc 2002;36:106-110.

5. Loder RT, Skopelja EN. The epidemiology and demographics of hip dysplasia. Orthop 2011:238607. https://doi.org/10.5402/2011/238607. eCollection 2011.

6. Çekiç B, Erdem Toslak I, Sertkaya Ö, et al. Incidence and follow up outcomes of developmental hip dysplasia of newborns in the Western Mediterranean Region. Turk J Pediatr 2015;57:353-58.

7. Kolb A, Schweiger N, Pokorny MM, et al. Low incidence of early developmental dysplasia of the hip in universal ultrasonographic screening of newborns: analysis and evaluation of risk factors. International Orthopaedics (SICOT), https://doi. org/10.1007/s00264-015-2799-2, 2015.

8. Ortiz-Neira CL, Paolucci EO, Donnon T. A meta-analysis of common risk factors associated with the diagnosis of developmental dysplasia of the hip in newborns. Eur J Radiol 2012;81:344-351. https://doi.org/10.1016/j.ejrad.2011.11.003

9. Roposch A, Wright JG. Increased diagnostic information and understanding disease: uncertainty in the diagnosis of developmental hip dysplasia. Radiology 2007;242:355-9. https://doi.org/10.1148/radiol.2422051937

10. Graf R. The diagnosis of congenital hip-joint dislocation by the ultrasonic Compound treatment. Arch Orthop Trauma Surg 1980;97:117-133. https://doi.org/10.1007/BF00450934

11. Omeroglu H, Caylak R, Inan U. Ultrasonographic Graf, type Ila hip needs more consideration in newborn girls. J Child Orthop 2013;7:95-98. https://doi.org/10.1007/s11832-012-0476-1

12. Koşar P, Ergun E, Gökharman F, et al. Follow-up sonographic results for Graf type 2a hips association with risk factors for developmental dysplasia of the hip and instability. J Ultrasound Med 2011;30:677-683. https://doi.org/10.7863/jum.2011.30.5.677

13. Sewell MD, Eastwood. Screening and treatment in developmental dysplasia of the hip-where do we go from here? Int Orthop 2011;35:1359-1367.

https://doi.org/10.1007/s00264-011-1257-z

14. Roovers EA, Boere-Boonekamp MM, Mostert AK, et al. The natural history of developmental dysplasia of the hip: sonographic findings in infants of 1-3 months of age. J Pediatr Orthop B 2005;14:325-330.

https://doi.org/10.1097/01202412-200509000-00003

15. Erol B, Kara T, Gurses C, et al. Gray scale histogram analysis of solid breast lesions with ultrasonography: can lesion echogenicity ratio be used to differentiate the malignancy? Clin Imaging 2013;37:871-5. https://doi.org/10.1016/j.clinimag.2013.04.007 